\title{
Electron microscopic changes in Enterocytozoon bieneusi following treatment with albendazole
}

\author{
C Blanshard, D S Ellis, S P Dowell, G Tovey, B G Gazzard
}

\begin{abstract}
Aim-To identify and describe electron microscopic changes occurring in Enterocytozoon bieneusi in patients treated with albendazole.

Methods-Eighteen HIV seropositive patients with $E$ bieneusi infection of the small intestine were treated with albendazole $\mathbf{4 0 0} \mathbf{~ m g}$ twice a day for one month. Duodenal biopsy specimens obtained before and at the end of treatment were examined electron microscopically by a pathologist who was unaware of the clinical response. A semiquantitative assessment of the parasite load and description of the parasite morphology was made.

Results-A complete resolution of diarrhoea occurred in nine patients and a further three had a greater than $50 \%$ reduction in baseline stool frequency or volume. Three of the non-responders were also infected with cryptosporidium. There was a reduction in parasite load in those responding to treatment and an increase in abnormal forms in both responders and non-responders.

Conclusion-The clinical response to albendazole treatment seen in some patients with small intestine microsporidiosis may be due to damage to the developmental stages, causing a partial inhibition of parasite reproduction.
\end{abstract}

(F Clin Pathol 1993;46:898-902)

Small intestine infection with microsporidia is an important cause of chronic diarrhoea in patients infected with HIV. Two recent series have suggested that the infection is present in about a third of patients with no other pathogen identified on stool examination and rectal biopsy specimen. ${ }^{12}$

The most common species described in all series is Enterocytozoon bieneusi, but recent reports have suggested that another species (Cali A and Beaugerie L, et al, abstracts presented at the workshop on Intestinal Microsporidia in HIV infection, Paris, 1992.), ${ }^{3-6}$ tentatively named Septata intestinalis also occurs. ${ }^{5}$

Although several drugs have been given to patients with small intestine microsporidiosis, there has as yet been no report of a treatment which eradicates the infection. Some workers have noted an improvement in the diarrhoea after treatment with metronidazole, ${ }^{16}$ but this has not been confirmed by others. ${ }^{7}$ (Hing $M$, et al. Abstract presented at the 8th International Conference on AIDS, Amsterdam, 1992.) We reported complete resolution of the diarrhoea symptoms in six patients treated with albendazole in a small open pilot study ${ }^{8}$ and noted that degenerative abnormalities were seen in the parasites in biopsy specimens after treatment, suggesting that the improvement in the symptoms was due to an effect of the drug on the organism rather than a non-specific effect on the intestinal flora. In an in vitro model using Encephalitozoon cuniculi pronounced abnormalities occurred when albendazole was added to the culture medium (EU Canning, personal communication). We now report our experience with albendazole in a larger group of patients.

\section{Methods}

All 18 patients who had microsporidia identified in small bowel biopsy specimens by electron microscopy and who were receiving albendazole independent of ongoing doubleblind placebo controlled trial were included in the study. This includes those treated as part of the initial open label pilot study. In 14 patients microsporidia were the only cause of diarrhoea present at the start of treatment; three also had cryptosporidiosis; and one had infiltration of the small bowel with $\mathrm{Myco-}$ bacterium avium intracellulare. These additional infections were diagnosed at the same time as the microsporidial infection.

All patients received an initial course of albendazole $400 \mathrm{mg}$ twice a day for one month. If there was a complete or partial improvement in the diarrhoea the drug was discontinued and the patient monitored for relapse. If there was no clinical response after one month treatment was continued at the same dose for a further month before defining the patient as a treament failure. All patients who relapsed were offered a further induction course followed by maintenance treatment at $200 \mathrm{mg}$ twice a day.

Response was monitored by charting daily stool frequency or volume, dose of antidiarrhoeal drugs, and body weight. A complete response was defined as cessation of diarrhoea (stool frequency of less than three times per day) without antidiarrhoeal treatment and a stabilisation of body weight. A partial response was defined as a more than $50 \%$ reduction in baseline stool frequency or volume while taking the same or a lower dose of antidiarrhoeals, but with continuing weight loss. 
Biopsy specimens were obtained from the third part of the duodenum at fibreoptic endoscopy before and after one month's treatment. In those patients continuing to take albendazole as maintenance therapy, further biopsy specimens were obtained at intervals throughout treatment.

At each endoscopy two biopsy specimens from different sites in the distal duodenum were processed for electron microscopy. Specimens were fixed in 3\% gluteraldehyde in $0.075 \mathrm{M}$ cacodylate buffer, containing $0.01 \%$ calcium chloride ( $\mathrm{pH} 7 \cdot 4$ ) for $12-24$ hours at $4^{\circ} \mathrm{C}$. They were washed overnight, cut into $2 \mathrm{~mm}$ cubes, fixed in $1 \%$ osmium tetroxide for 1 hour at $4^{\circ} \mathrm{C}$, block stained with $2 \%$ uranyl acetate, dehydrated through graded methanol solutions, and embedded in Taab resin via propylene oxide. Semithin $(0.5-1 \mu \mathrm{m})$ sections were examined after staining with toluidene blue, and ultrathin sections (pale gold spreading to silver) were cut from infected areas of the mucosa and stained with Reynold's lead citrate.

The biopsy specimens were examined by a pathologist who was not informed of the patients' treatment regimens or whether there had been a clinical response. For each biopsy specimen, the number of parasites was estimated on the toluidine blue stained sections and the infection was graded as: heavy (more than half the enterocytes in the distal half of the villus infected, with infection spreading to the proximal villus); moderate (multiple cells in most villi infected, but less than half of the distal villus cells parasitised); and light (only a few scattered parasites per section). About 30 parasites, occupying at least two representative grids from different blocks, were examined in more detail and a semiquantitative assessment was made of the number of abnormal forms at each stage of parasite devel- opment. These were reported as + (less than $10 \%$ of parasites abnormal), ++ (more than $30 \%$ abnormal), and +++ (more than $60 \%$ abnormal). Abnormalities were defined on the basis of severe deviations from the normal morphology of the parasite ${ }^{9}{ }^{10}$ :- for example, the presence of non-dividing nuclei with an irregular outline, outpocketing, and destruction of the nuclear membranes, disruption or vacuolation of the cytoplasm, abnormal inclusions, disruption of the cell membrane and the presence of multinucleate or grossly enlarged spores. Care was taken to assess only areas away from the edges of the biopsy specimen to avoid traumatic artefact.

\section{Results}

Seventeen patients were infected with $E$ bieneusi, diagnosed on the basis of its unique ultrastructural morphology: the proliferative phases are multinucleate and lie free in the cytoplasm. Electron lucent inclusions occur in the cytoplasm and electron-dense discs, which are thought to be precursors of the polar tubes, appear in the sporonts. There is delayed deposition of the sporont coat and the spores are produced by multiple fission of the sporont. The spores are very small (1-1.6 $\mu \mathrm{m}$ in length) and have a poorly developed endospore layer. The polar filament is organised into a single row of four to six coils.

One patient was infected with both $E$ bienesi and a second species which could be differentiated by its occurrence in a parasitophorous vacuole and larger spores. There were too few developmental stages present, however, to identify the species at electron microscopy.

A complete clinical response was seen in nine patients and a partial response in three (table). Three of the non-responders were also infected with cryptosporidium.

Results of treatment with albendazole in 18 patients with small intestine microsporidiosis

\begin{tabular}{|c|c|c|c|c|c|c|c|}
\hline \multirow[b]{2}{*}{ Case no } & \multirow{2}{*}{$\begin{array}{l}\text { Clinical } \\
\text { response }\end{array}$} & \multicolumn{2}{|c|}{ Parasite load } & \multicolumn{2}{|c|}{ Abnormal forms } & \multirow{2}{*}{$\begin{array}{l}\text { Maintenance } \\
\text { therapy }\end{array}$} & \multirow[b]{2}{*}{ Follow up } \\
\hline & & Before & After & Before & After & & \\
\hline $\begin{array}{l}1 \\
2 \\
3 \\
4\end{array}$ & $\begin{array}{l}\text { CR } \\
\text { PR } \\
\text { CR } \\
\text { CR }\end{array}$ & $\begin{array}{l}\text { Light } \\
\text { Heavy } \\
\text { Moderate } \\
\text { Moderate }\end{array}$ & $\begin{array}{l}\text { Light } \\
\text { Moderate } \\
\text { NA } \\
\text { Moderate }\end{array}$ & $\begin{array}{l}+ \\
+ \\
+ \\
+\end{array}$ & $\begin{array}{l}+++ \\
+++ \\
\text { NA } \\
++\end{array}$ & $\begin{array}{l}\text { Yes } \\
\text { Yes } \\
\text { No } \\
\text { Yes }\end{array}$ & $\begin{array}{l}\text { Died, no diarrhoea, } 16 \mathrm{~m} \\
\text { Died, no diarrhoea, } 17 \mathrm{~m} \\
\text { Died, no diarrhoea, } 1 \text { week } \\
\text { Developed cryptosporidiosis } \\
\text { Died with diarrhoea, } 4 \mathrm{~m}\end{array}$ \\
\hline 5 & CR & Moderate & Light & + & ++ & No & $\begin{array}{l}\text { Diarrhoea recurred after stopping } \\
\text { Declined further treatment, alive } 21 \mathrm{~m}\end{array}$ \\
\hline $\begin{array}{l}14 \\
15 \\
16\end{array}$ & $\begin{array}{l}\text { NR } \\
\text { CR } \\
\text { PR }\end{array}$ & $\begin{array}{l}\text { Heavy } \\
\text { Heavy } \\
\text { Heavy }\end{array}$ & $\begin{array}{l}\text { Heavy } \\
\text { Moderate } \\
\text { NA }\end{array}$ & $\begin{array}{l}+ \\
+ \\
+\end{array}++$ & $\begin{array}{l}+++ \\
++ \\
\mathrm{NA}\end{array}$ & $\begin{array}{l}\text { No } \\
\text { Yes } \\
\text { Yes }\end{array}$ & $\begin{array}{l}\text { Died, severe diarrhoea, } 5 \mathrm{~m} \\
\text { Died, no diarthoea, } 22 \mathrm{~m} \\
\text { Diarrhoea settled completely after } \\
\text { maintenance therapy. Stopped treatment } \\
\text { after } 3 \mathrm{~m} \text {, repeat biopsy } 2 \mathrm{~m} \text { later: light } \\
\text { infection, }+ \text { abnormalities. Died, no } \\
\text { diarrhoea } 13 \mathrm{~m}\end{array}$ \\
\hline $\begin{array}{l}17 \\
18\end{array}$ & $\begin{array}{l}\text { NR } \\
\text { CR }\end{array}$ & $\begin{array}{l}\text { Moderate } \\
\text { Heavy }\end{array}$ & $\begin{array}{l}\text { Moderate } \\
\text { Moderate }\end{array}$ & $\begin{array}{l}+ \\
+\end{array}$ & $\begin{array}{l}++ \\
+++\end{array}$ & $\begin{array}{l}\text { No } \\
\text { No }\end{array}$ & $\begin{array}{l}\text { Died with diarrhoea } 1 \mathrm{~m} \\
\text { Treated for } 5 \mathrm{~m} \text {. Diarrhoea recurred off } \\
\text { treatment but controlled by opiates } \\
\text { Alive } 23 \mathrm{~m}\end{array}$ \\
\hline
\end{tabular}

Survival figures are calculated from the time of diagnosis of microsporidiosis. Results after treatment are from biopsy specimens obtained after one month's treatment. CR: Complete response; PR: partial response; NR: no response; NA: biopsy specimen at one month not available because the patient died during induction treatment (case 3) or was lost to follow up (case 7). Case 16 failed to attend for biopsy at one month but specimens were obtained on maintenance treatment. LFU: lost to follow up; m: months. 


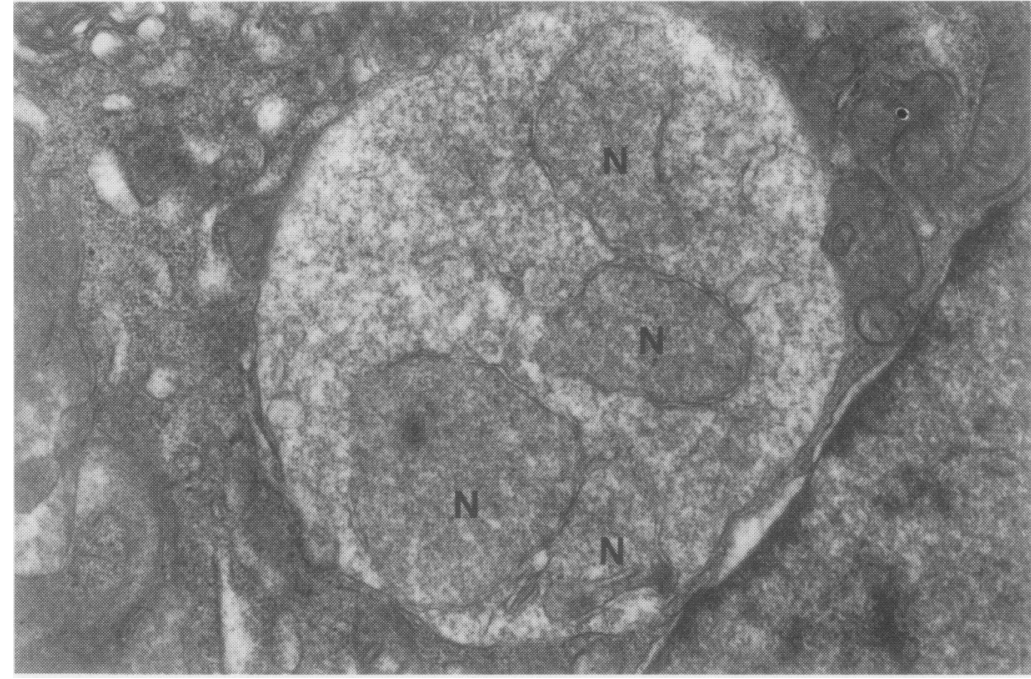

Figure $1 A$ Normal early meront in a biopsy specimen taken before treatment. The organism is in direct contact with the host cell cytoplasm and contains four ovoid nuclei $(N)$.

Figure $1 B$ Parasite at a similar stage of development in a biopsy specimen after treatment. The nuclei (N) are deformed and vacuolated with apparent separation of the nuclear membrane from the nucleoplasm.

Figure 1C Another early meront in a biopsy specimen after treatment containing three large membrane whorls. These have not been described in normal microsporidia.
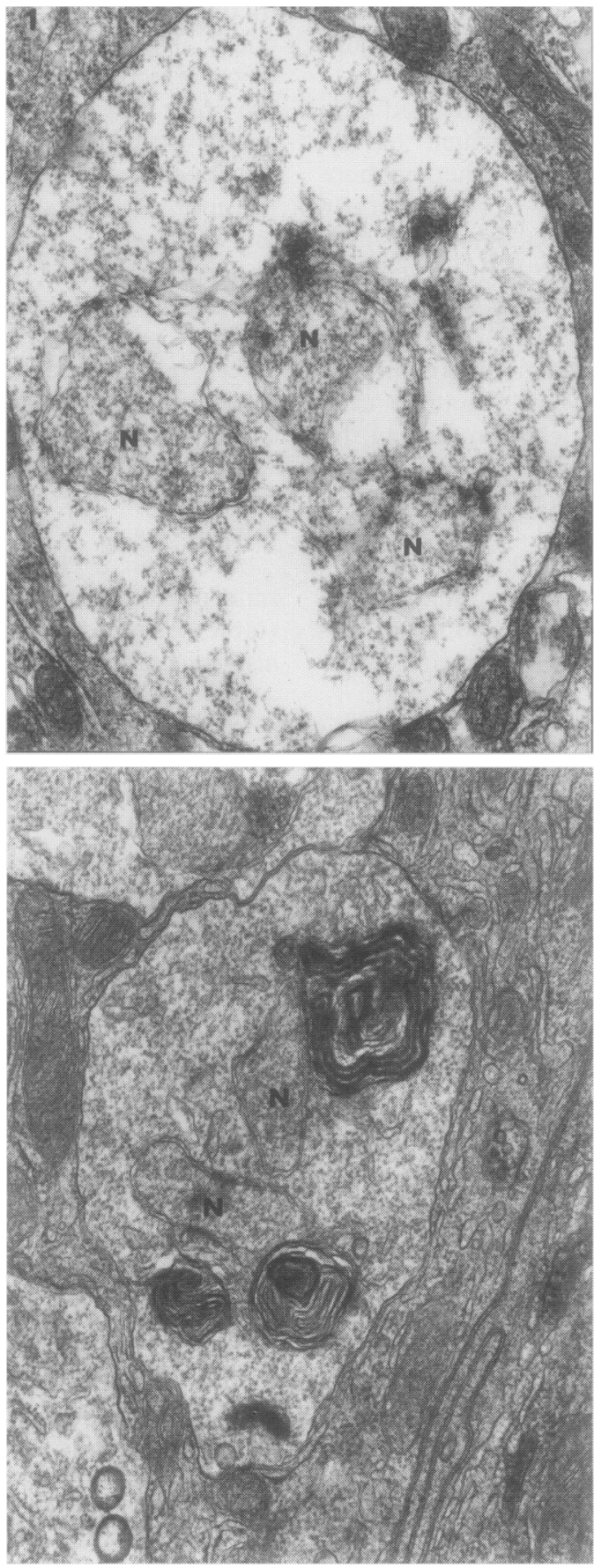

ELECTRON MICROSCOPIC EXAMINATION

Pairs of biopsy specimens taken at the same time showed similar levels of infection. There was a minor variation in the actual number of parasites in each section examined, but in no case was the density of infection in the two specimens graded differently.

\section{Before treatment}

There was no correlation between the heaviness of the initial infection and the severity of the diarrhoea, the duration of symptoms before diagnosis, or the CD4 count of the patient. Occasional damage or an abnormality was found among a minority of the parasites in untreated patients, usually limited to a few vacuolated proliferative plasmodia or deformed mature spores. In only one specimen taken before treatment were more than $10 \%$ of the parasites abnormal.

\section{After one month of albendazole treatment}

During treatment, all but two specimens showed a higher incidence of abnormalities in the parasites $(++$ to +++$)$. Six of the responders had an apparent decrease in the parasite load after treatment compared with none of the non-responders $(p=0.04$, Fisher's exact test). In no patient, however, had the infection been eliminated over a follow up period of three to 18 months of treatment. Similar abnormalities occurred in all specimens taken after treatment, and the degree of abnormality did not correlate with clinical response. Abnormalities occurred at all stages of the parasite's life cycle but were most obvious in the proliferative phases (figs 1-3). In the meronts cytoplasmic vacuoles were seen, some of which were surrounded by incomplete membranes (fig 1B). The nuclei were often irregular in outline, with disruption of the nuclear membranes and electron lucent vacuoles between the nucleoplasm and the membrane (fig 1B). There was proliferation of the rough endoplasmic reticulum, and membrane whorls were found in the cytoplasm (fig $1 \mathrm{C}$ ). In the sporonts some developing polar tubes were swollen and pale (fig 2B). Enlarged parasites sometimes had incomplete or ballooned plasmalemmata. Some organisms contained abnormal lipidlike inclusions. Abnormal, enlarged spores were seen, some containing multiple nuclei and sets of organelles, suggesting incomplete division of the sporonts (fig 3B).

\section{After albendazole treatment}

Four patients who relapsed after successful treatment had follow up biopsy specimens obtained after more than a month without albendazole. In these specimens less than $10 \%$ of the parasites were abnormal. Six patients who remained in remission while receiving albendazole maintenance therapy had follow up biopsy specimens taken which continued to show pronounced abnormalities in the parasites. 


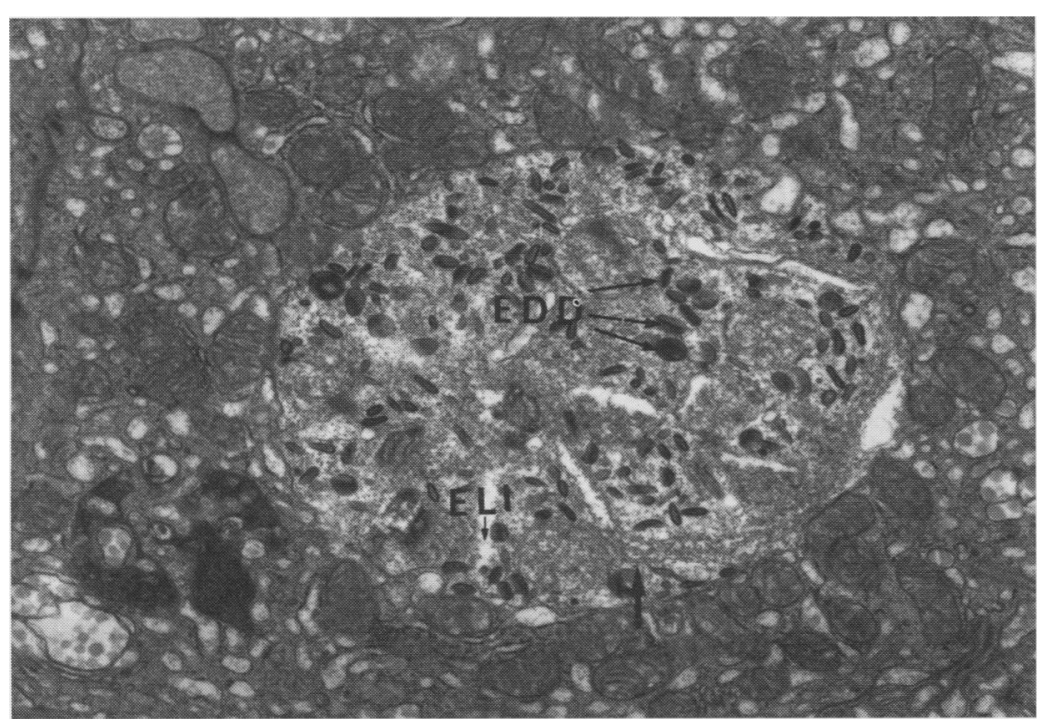

Figure $2 A$ Normal sporogonic plasmodium in an untreated patient. This stage of development is characterised by the presence of electron dense discs (EDD), precursors of the polar tube. Rough endoplasmic reticulum appears at this stage but is sparsely distributed throughout the cell (heavy arrows). Electron lucent inclusions (ELI) are also present.

Figure 2B Parasite at a similar stage of development in the same patient after treatment. Many nuclei (n) are present as in Fig $2 A$, but the cell is packed with endoplasmic reticulum (ER). Although many of the electron dense discs are developing normally into the polar tube $(F)$ some are abnormally electron lucent and disorganised (arrowed).

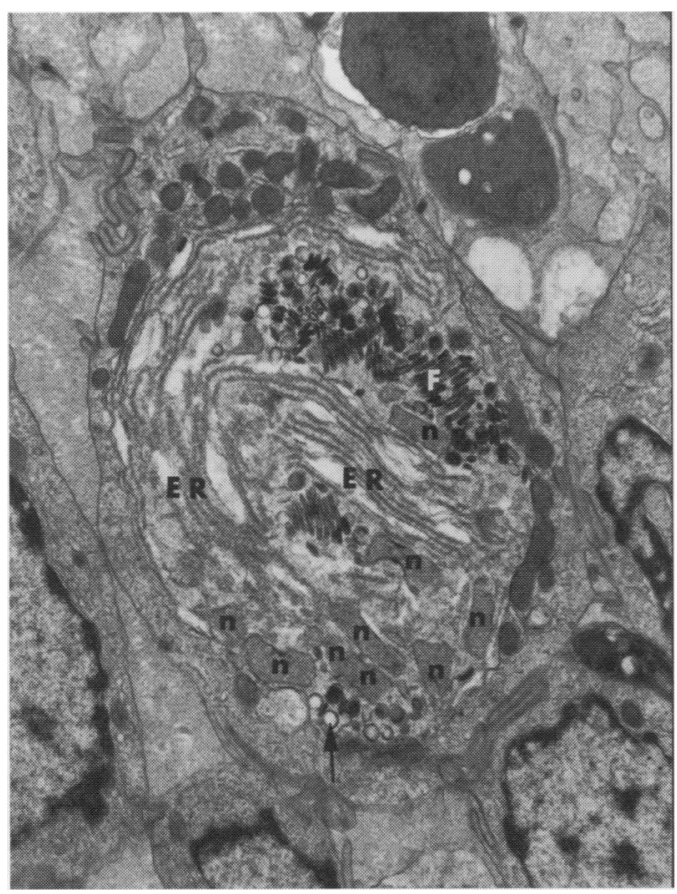

\section{Discussion}

Albendazole is a partially absorbed benzimidazole carbamate with a broad spectrum of antiparasitic activity against both protozoa and helminths. It has been successfully used in the treatment of giardiasis, ${ }^{11}$ intestinal nematodes, and systemic helminth infections such as hydatid cyst disease, ${ }^{12}$ in doses similar to those used here. Following the publication of our initial report of the use of albendazole in the treatment of small intestine microsporidiosis, other groups have tried the drug with some success, (abstracts presented at the 8th International Conference on AIDS) although the response rate varies widely. ${ }^{\text {? }}$ Clinical and radiological improvement has been seen in a patient with chronic microsporidial infection of the sinuses and conjunctivae following oral albendazole treatment, although repeat biopsy specimens were not obtained. ${ }^{13}$ There is strongly suggestive evidence that the drug may eliminate infection with Septata intestinalis (Abstracts presented at the 8th International conference on AIDS). Pronounced abnormalities are seen at electron microscopy following treatment of microsporidia in vitro with albendazole (Canning EU, unpublished observations).

This study suggests that the clinical efficacy of albendazole is related to a direct effect of the drug on the parasite, as pronounced abnormalities in the organism are detected by electron microscopy during treatment. Although occasional abnormalities are observed in parasites from untreated patients, the abnormalities are much more common during treatment. Albendazole binds to the colchicine sensitive site of tubulin, inhibiting its polymerisation into microtubules and thus interfering with nutrient uptake and cell division. ${ }^{14}$ Giardia lamblia treated with the drug in vitro develops abnormal aggregates of endoplasmic reticulum similar to those seen in some organisms in this study. ${ }^{15}$ Microtubules are important in the formation of spindles allowing nuclear division in microsporidia, and abnormally large forms of microsporidia, suggesting incomplete division of the proliferative stages, have been seen in in vitro models in other studies (Canning EU, unpublished observations). The other changes observed have not been described before. Patients who responded to the drug tended to have a reduction in parasite load during treatment. Although this finding must be interpreted with caution because of the potential sampling error inherent in measurements made on only two biopsy specimens, we found that the infection seemed to be evenly distributed in the distal duodenum so that the density of infection in each of the pairs of specimens was similarly graded. The small differences observed between specimens taken on the same occasion contrasted with the noticeable reduction in the parasite load in patients responding to treatment. We believe that the damage to the microsporidia caused by the drug probably inhibits parasite reproduction, resulting in a gradual decrease in parasite load during treatment. Albendazole clearly does not completely arrest development of the parasite otherwise the infection would be eliminated by the normal turnover of enterocytes and normal spores would not be seen in treated patients.

Twenty nine per cent of patients treated failed to respond to the drug. In some cases this may have been due to additional infections. Three of the non-responders had confirmed cryptosporidiosis with large numbers of organisms in stools and biopsy specimens. Others may have had undiagnosed additional intestinal infections. Alternatively, in some patients tissue concentrations of albendazole may have been below the therapeutic range. Follo:ving oral ingestion, albendazole is metabolised in the liver, mainly to a sulphoxide, which is thought to be the active com- 


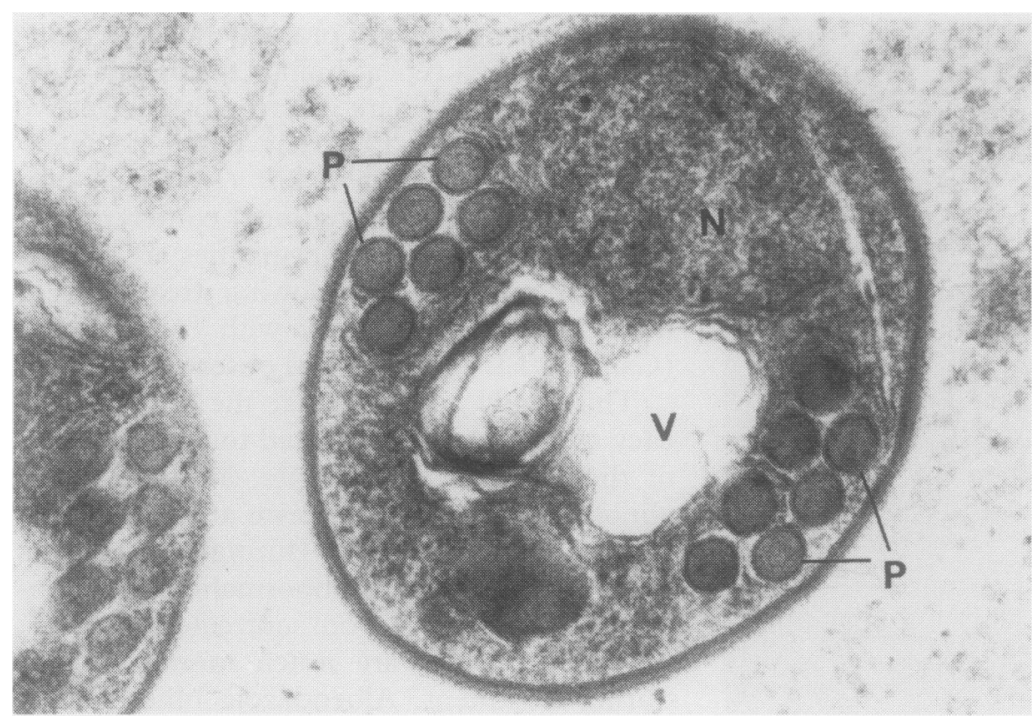

Figure $3 A$ Normal mature spore, oval in shape and measuring 1-1.64 $\mu \mathrm{m}$ in length. There is a single nucleus (N), a posterior vacuole (V), and a double row of coils of the polar tube (P).

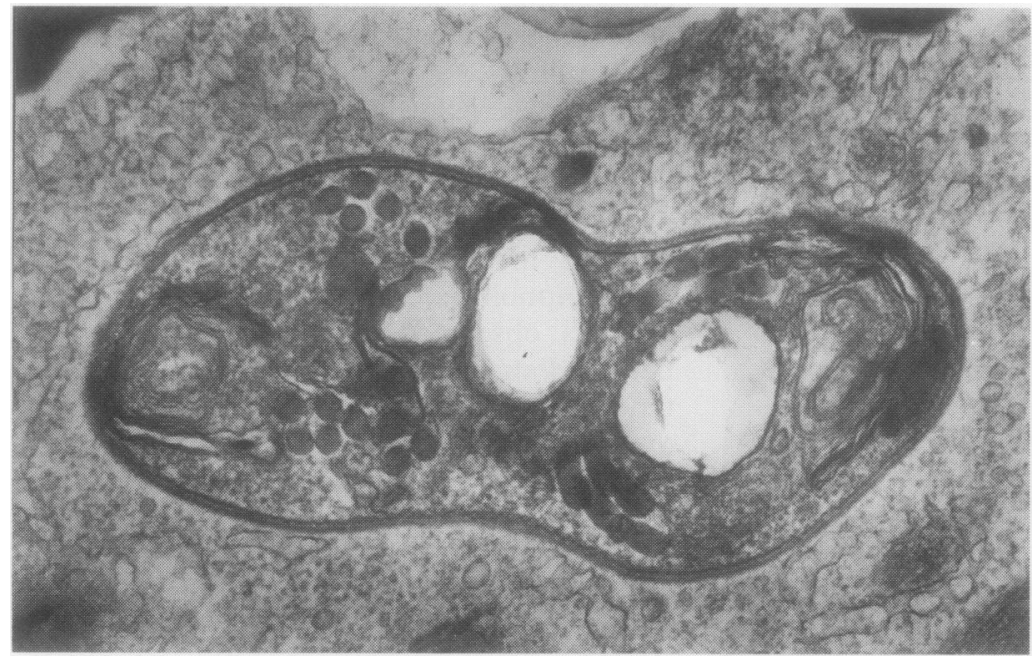

Figure 3B Giant spore from a treated patient, containing a polaroplast at each pole and two nuclei, coils of the polar filament and two vacuoles, suggesting that an earlier division process has been aborted. not expect to see evidence of damage to the parasite in biopsy specimens taken after treatment.

The partial inhibition of parasite reproduction is consistent with the observation that relapse of diarrhoea occurs rapidly after discontinuing treatment. Maintenance therapy, however, is well tolerated, with no major toxicity seen, and experience from the treatment of hydatid cyst disease suggests that albendazole is safe in long term use.

The full potential of albendazole should now be assessed in a controlled clinical trial. A double blind placebo controlled crossover study is under way in two European centres and a similar trial is planned in the United States. Such trials should include measurement of the plasma concentrations of albendazole sulphoxide to determine whether therapeutic failure is due to lack of absorption of the drug. There is also an urgent need to develop in vitro or animal models to test other drugs for efficacy against this important intestinal pathogen.

1 Orenstein JM, Chiang J, Steinberg W, Smith PD, Rotterdam H, Kotler DP. Intestinal microsporidiosis as a cause of diarrhoea in human immunodeficiency virusinfected subjects. A report of 20 cases. Hum Pathol 1990;21:475-81.

2 Eeftinck Schattenkerk JKM, Van Gool T, Van Ketel RJ, et al. Clinical sienificance of small intestinal microsporidiosis in HIV-1 infected individuals. Lancet 1991; 337:895-8.

3 Blanshard C, Hollister WS, Peacock CS, et al. Simultaneous infection with two types of intestinal microsporidia in a patient with AIDS. Gut 1992;33: 418-20.

4 Orenstein JM, Tenner M, Cali A, Kotler DP. A microsporidian previously undescribed in humans, infecting enterocytes and macrophages, and associated with diarrhoea in an acquired immunodeficiency syndrome patient. Hum Pathol 1992;23:722-8.

5 Cali A. Intestinal microsporidioses and their agents: comparative cytological and taxonomical data obtained from both microsporidian species responsible for intestinal infections. Fournal of Acquired Immunodeficiency Syndromes 1993; (in press).

6 Beaugerie L, Teilhac MF, Deluol AM, et al. Cholangiopathy associated with microsporidia infection of the common bile duct mucosa in a patient with HIV infection. Ann Int Med 1992;117:401-2.

7 Blanshard C, Gazzard BG. Microsporidiosis in HIV-1 infected individuals. Lancet 1991;338:1488.

8 Blanshard C, Ellis DS, Tovey DG, Dowell S, Gazzard BG. Treatment of intestinal microsporidiosis with albendreale in patients with AIDS. AIDS 1992;6:311-3.

9 Cali A, Owen RL. Intracellular development of Enterocytozoon, a unique microsporidian found in the intescytozoon, a unique microsporidian found in the
tine of AIDS patients. $₹$ Protozool 1990;37:145-55.

10 Canning EU, Lom J. The microsporidia of vertebrates. London: Academic Press, 1986.

pound. Albendazole sulphoxide is detectable in the plasma and reaches peak concentrations in a mean of 4.33 hours after ingestion of an oral dose. ${ }^{16}$ The pharmacokinetics vary highly from person to person with a $54 \%$ variation in the maximum plasma concentrations achieved and an even greater variability in the minimum levels. ${ }^{16}$ This is thought to be due to differences in the absorption of the drug. ${ }^{17}$ Malabsorption is a common feature of small bowel infection with microsporidia, ${ }^{18}$ and some patients may not achieve the necessary plasma concentrations to inhibit parasite replication. Finally, there may be partial resistance of some strains of the parasite to the drug. Benzimidazole resistance occurs in nematodes due to mutation in the $\beta$-tubulin molecule after treatment. ${ }^{19}$ If therapeutic failure were due to low tissue concentrations or benzimidazole resistance, however, we would Di Rosa S, Affronti M, Malta $R$, et al. The treatment of
giardiasis with albendazole. $\mathcal{F}$ Chemother 1989;1(suppl): 948.

12 Horton RJ. Chemotherapy of Echinococcus infection in man with albendazole. Trans Roy Soc Trop Med Hyg 1989;83:97-102.

13 Lacey CJN, Clarke AMT, Fraser P, Metcalfe T, Bonsor $\mathrm{G}$, Curry A. Chronic microsporidian infection of the nasal mucosae, sinuses and conjunctivae in HIV disease. Genitourin Med 1992;68:179-81.

14 Lacey E. Mode of action of benzimidazoles. Parasitol Today 1990;6:112-5.

15 Edlind TD, Hang TL, Chakraborty PR. Activity of antihelminthic benzimidazoles against Giardia lamblia in vitro. $\mathcal{F}$ Infect $D$ is 1990;62:1408-11.

16 Jung $H$, Hurtando $M$, Sanchez M, Medina MT, Sotelo J. Clinical pharmacokinetics of albendazole in patients with brain cysticercosis. I Clin Pharmacol 1992;32: 705-8.

17 Marriner SE, Morris DL, Dickson B, Bogan JA. Pharmacokinetics of albendazole in man. Eur $\Im$ Clin Pharmacol 1986;30:705-8.

18 Blanshard C, Dowell S, Ellis DS, Canning EU, Gazzard BG. Small intestinal microsporidiosis in HIV infection: a report of 22 cases. Gut 1992;33:T177.

19 Roos S. The molecular nature of benzimidazole resistance in helminths. Parasitol Today 1990;6:125-7. 